\title{
Implementasi Pengujian Black Box menggunakan Teknik Equivalents Partitions pada Aplikasi Pendaftaran Commuter Line Berbasis Web
}

\author{
M. Diky Oktafian ${ }^{1}$, M. Azi Haetami², M. Jibril ${ }^{3}$, Reyhan Said ${ }^{4}$, Teti Desyani ${ }^{5}$ \\ Teknik Informatika, Universitas Pamulang, Jl. Raya Puspitek No.46, Buaran, Serpong, Tangerang \\ Selatan, Banten, Indonesia, 15310 \\ E-mail: 1dikyoktafian25@gmail.com, ${ }^{2}$ haetami97@gmail.com, ${ }^{3}$ mujibumi@gmail.com, \\ ${ }^{4}$ reyhansaid.rs@gmail.com, ${ }^{5}$ dosen00839@unpam.ac.id
}

Submitted Date: June $03^{\text {rd }}, 2020$

Revised Date: August $02^{\text {nd }}, 2020$
Reviewed Date: July $19^{\text {th }}, 2020$

Accepted Date: August 02 $2^{\text {nd }}, 2020$

\begin{abstract}
Computer Program that contains defectives (mistakes) can cause a disadvantage that can affect to stakeholders. The disadvantaged can take the shape of money related, time, and others. So sometime recently the program is executed it has to be testing. Testing on an application proposed to check the program is running legitimately or not. In testing, this computer program will utilize Black Box Testing. Black Box Testing Strategy had a few strategies, Equivalence Partitions, Boundary Value Analysis, Sample Testing, etc. From many testing methods, we will use the Equivalence Partitions. Equivalence Partitions method is a test based on data input for each form where the application system of performance data information each menu input would be tested and grouped accord to the function whether valid or invalid. Testing is doing on the Application form that will be in the content from the data that suitable with personal data. The final results show there is still much lack when valid data will be inputted causes data stored in the database to be incompatible with the expected data. The results of this test would be used to improve the application at performance data for the future. In the end, the application could handle normal and abnormal data with a percentage of success $91,67 \%$.
\end{abstract}

Keywords: Application; Testing; Black Box; Equivalence Partitions; Commuter Line Registration

\section{Abstrak}

Perangkat lunak yang mengandung cacat (kesalahan) dapat menimbulkan kerugian. Kerugian yang diakibatkan dapat berdampak pada semua stakeholder. Kerugian dapat berbentuk finansial, waktu, dan lainlain. Sehingga sebelum perangkat lunak diimplementasikan perlu dilakukan pengujian. Pengujian pada suatu aplikasi bertujuan memeriksa program pada aplikasi apabila telah berfungsi dengan semestinya. Pada pengujian perangkat lunak ini akan menggunakan Blackbox Testing. Metode Black Box Testing memiliki beberapa teknik, Equivalence Partitions, Boundary Value Analysis, Sample Testing, dan sebagainya. Di antara banyak teknik pengujian tersebut, pada penelitian ini dipilih teknik pengujian menggunakan Equivalence Partitions. Teknik Equivalence Partitions merupakan sebuah pengujian berdasarkan masukan data pada setiap form yang ada pada sistem aplikasi informasi data kinerja, setiap menu masukan akan dilakukan pengujian dan dikelompokkan berdasarkan fungsinya baik itu bernilai valid ataupun tidak valid. Pengujian dilakukan pada 1 form pendaftaran yang akan di isi dengan data sesuai data pribadi. Hasil sebuah pengujian dapat menunjukkan adanya kesalahan ketika pengguna melakukan validasi data yang akan dimasukkan, akhirnya bisa menyebabkan data yang akan dimasukkan pada database tidak sesuai dengan data yang sudah dirancang. Hasil dari pengujian bisa jadi masukan untuk perbaikan aplikasi pada data kinerja di kedepannya. Pada akhirnya aplikasi dapat menangani data normal maupun tidak, dengan persentase keberhasilan $91,67 \%$.

Kata Kunci: Aplikasi; Pengujian; Black Box; Equivalence Partitions; Registrasi Commuter Line 


\section{Pendahuluan}

Penggunaan sistem informasi telah mengalami perkembangan yang sangat maju. Seiring dengan meningkatnya penggunaan dan berkembang teknologi informasi diikuti juga kebutuhan terhadap informasi secara efektif dan efesien sangat diperlukan. Sehingga rancangan teknologi informasi dan infrastrukturnya merupakan suatu yang mutlak untuk dibuat dengan mempertimbangkan masa depan. Sistem informasi adalah satu kumpulan dari sistem-sistem yang saling terintregasi dan menghasilkan suatu informasi yang bermanfaat bagi pemakainya (Taufiq, Magfiroh, Yusup, \& Yulianti, 2020). Sistem informasi berguna untuk melakukan pengelolahan data yang akan menghasilkan informasi yang berkualitas. Untuk menjamin kualitas sistem/aplikasi yang dikembangkan harus melalui tahap pengujian (Pratala, Asyer, Prayudi, \& Saifudin, 2020).

Pengujian pada sebuah program sangat penting untuk dilakukan untuk memeriksa semua kesalahan yang ada pada program tersebut agar tidak terjadi kerugian yang akan ditimbulkan dari kesalahan tersebut, maka perlu dilakukan pengujian untuk mencegah terjadinya kesalahan yang dapat merugikan (Ningrum, Suherman, Aryanti, Prasetya, \& Saifudin, 2019). Pada Sistem Aplikasi Form Pendaftaran Berbasis Web ini bertujuan untuk mengetahui kualitas keamanan. Hasil dari penilaian dalam Sistem Aplikasi Form Pendaftaran Berbasis Web ini dapat memberikan sebuah pertimbangan bagi manager atau atasan dalam pengambilan keputusan untuk menilai sistem kemanannya.

Dalam melakukan pengujian harus memilih teknik yang tepat, yaitu teknik yang dapat menemukan kesalahan yang belum terdeteksi sehingga dapat meningkatkan kualitas software (Hendri, Manurung, Ferian, Hanaatmoko, \& Yulianti, 2020). Metode Black Box Testing yaitu metode untuk menguji sebuah perangkat lunak tanpa harus memperhatikan hal detail perangkat lunak. Pengujian ini hanya memeriksa nilai keluaran berdasarkan nilai masukan masingmasing (Hanifah, Alit, \& Sugiarto, 2016). Proses Black Box Testing dengan cara mencoba memasukan data pada setiap formnya. Pengujian ini sangat diperlukan apakah program yang dibuat sesuai atau tidak sesuai (Wahyudi, Utami, \& Arief, 2016).

Pengujian Black Box disebut juga sebagai Behavioral Testing yaitu metode pengujian perangkat lunak yang pengujinya tidak perlu mengetahui struktur internal, desain aplikasi, dan implementasian (pengkodean) dari perangkat lunak yang diuji. Pengujian Black Box ditujukan untuk menguji fungsionalitas dari perangkat lunak maupun nonfungsionalitasnya, walaupun kadang hanya menguji fungsionalitasnya saja.

Ada beberapa teknik dalam pengujian menggunakan Black Box Testing, salah satunya adalah menggunakan teknik Equivalence Partitions (Hidayat \& Muttaqin, 2018). Equivalence Partitions merupakan sebuah pengujian berdasarkan masukan data pada setiap form yang ada pada sistem aplikasi informasi data kinerja, setiap menu masukan akan dilakukan pengujian dan dikelompokkan berdasarkan fungsinya, baik itu hasilnya valid atau tidak valid (Aziz, Setiawan, Khanh, Nurdiyansyah, \& Yulianti, 2020).

Pada karya ilmiah ini ditujukan untuk menguji Aplikasi Pendaftaran Commuter Line yang berbasis website. Website disebut juga sebagai situs di internet yang dapat diartikan sebagai sekumpulan beberapa halaman yang ditujukan untuk menyediakan informasi teks, gambar diam maupun gerak, animasi, suara, dan gabungannya. Website membentuk suatu rangkaian bangunan berdasarkan jaringan-jaringan halaman yang saling terkait bersifat statis maupun dinamis.

\section{Metodologi}

Software yang cacat atau mengandung kesalahan dapat memberikan hasil yang tidak sesuai harapan dan dapat menyebabkan kerugian yang besar (Saifudin \& Yulianti, 2020). Pengujian terhadap perangkat lunak sangat penting dilakukan dengan maksud untuk memberikan jaminan kualitas perangkat lunak yang dihasilkan agar bebas dari terjadinya kesalahan (Debiyanti, Sutrisna, Budrio, Kamal, \& Yulianti, 2020).

Pengujian yang dilakukan pada Aplikasi Form Pendaftaran Berbasis Web ini menggunakan masukan data valid dan tidak valid dengan tujuan untuk memastikan sistem dapat merespon sesuai harapan, sehingga sistem teruji dengan berbagai kondisi dan dapat dinyatakan layak untuk digunakan. Pengujian aplikasi komputer termasuk suatu rangkaian aktivitas yang terencana dan sistematis untuk menguji atau mengevaluasi kebenaran fungsi aplikasi berdasarkan desain kasus uji (test case) yang spesifik (Yulistina, Nurmala, Supriawan, Juni, \& Saifudin, 2020). Dalam penelitian ini akan dilakukan beberapa tahapan. Pada tahapan pertama diawali dengan menentukan 
Test Case perangkat lunak yang akan diuji dengan metode Equivalence Partitions kemudian menginisialisasi standar grade partition masukan dan keluaran. Tahapan ini dilaksanakan untuk memperoleh dokumentasi pengujian menggunakan teknik Equivalence Partitions dan menilai tingkat efektifitasnya.
Sebelum pengujian dibuat kasus uji (Test Case) sebagai acuan pengujian berdasarkan teknik Equivalence Partitions untuk menyimpulkan apakah sistem telah bebas dari kesalahan dalam pengujian tersebut atau tidak (Arochman, Darmawan, \& Santoso, 2016). Berikut terdapat penjelasan dari tabel Test Case.

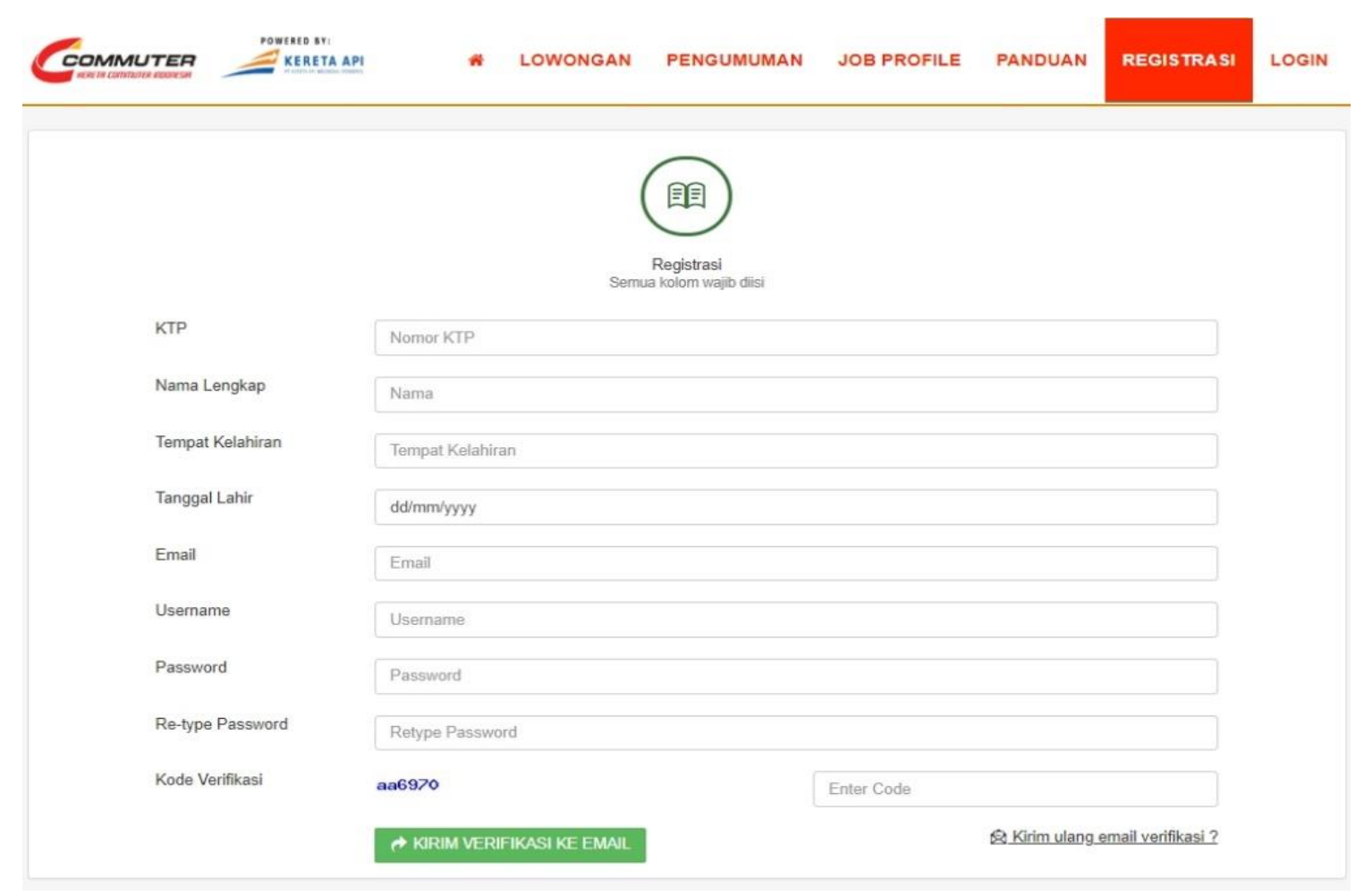

Gambar 1 Form Registrasi Commuter Line

Dari form pada Gambar 1 ada beberapa rencana pengujian. Form Pendaftaran diisi dengan mengisi KTP, Nama Lengkap, Tempat Kelahiran, Tanggal Lahir, Email, Username, Password, Retype Password dan Kode Verifikasi.
Dari form pada Gambar 2, Form Registrasi sudah di isi dengan benar dan valid sesuai dengan ketentuan, maka data dipastikan tersimpan di Database PT. Commuter Line. 


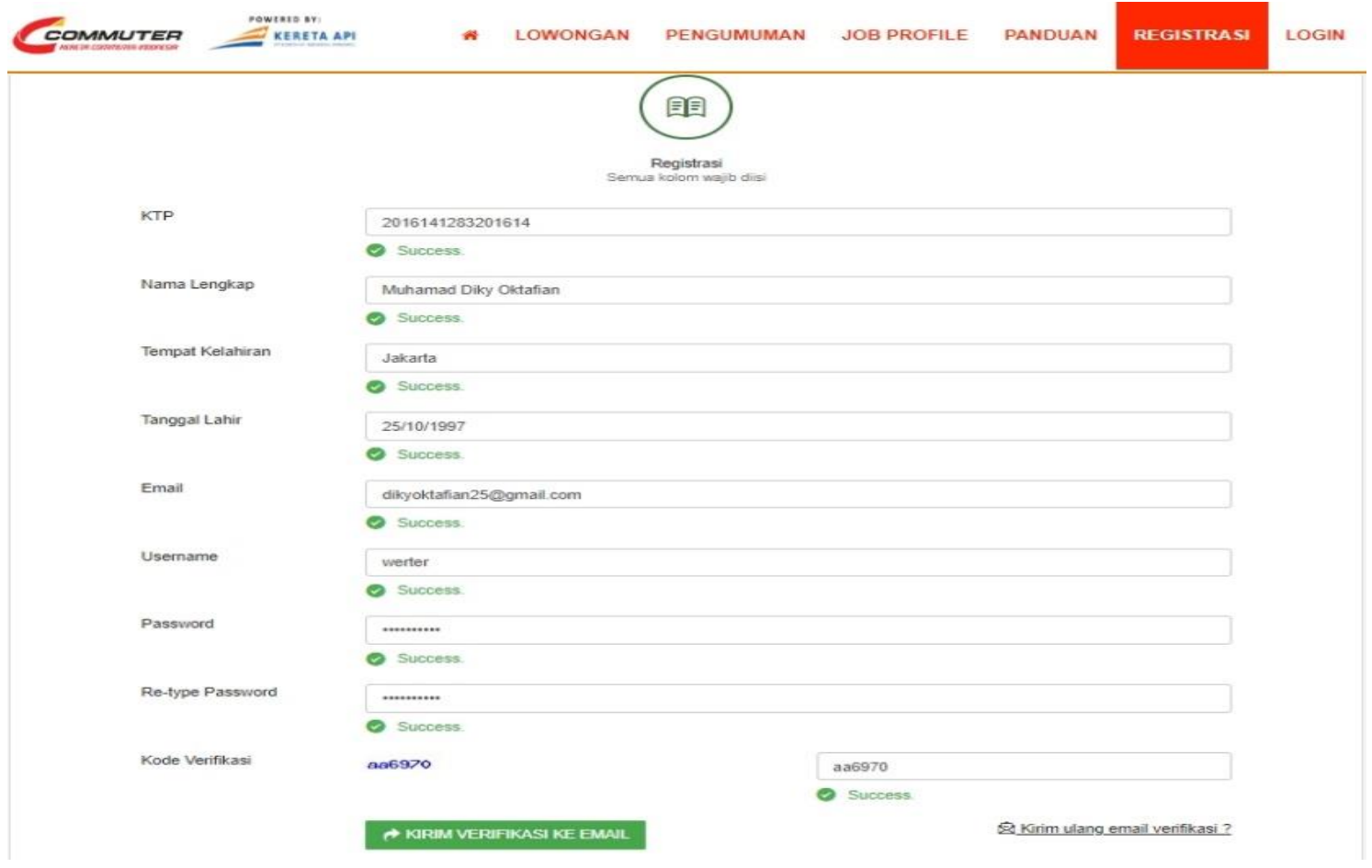

Gambar 2 Form Registrasi Commuter Line diisi data valid

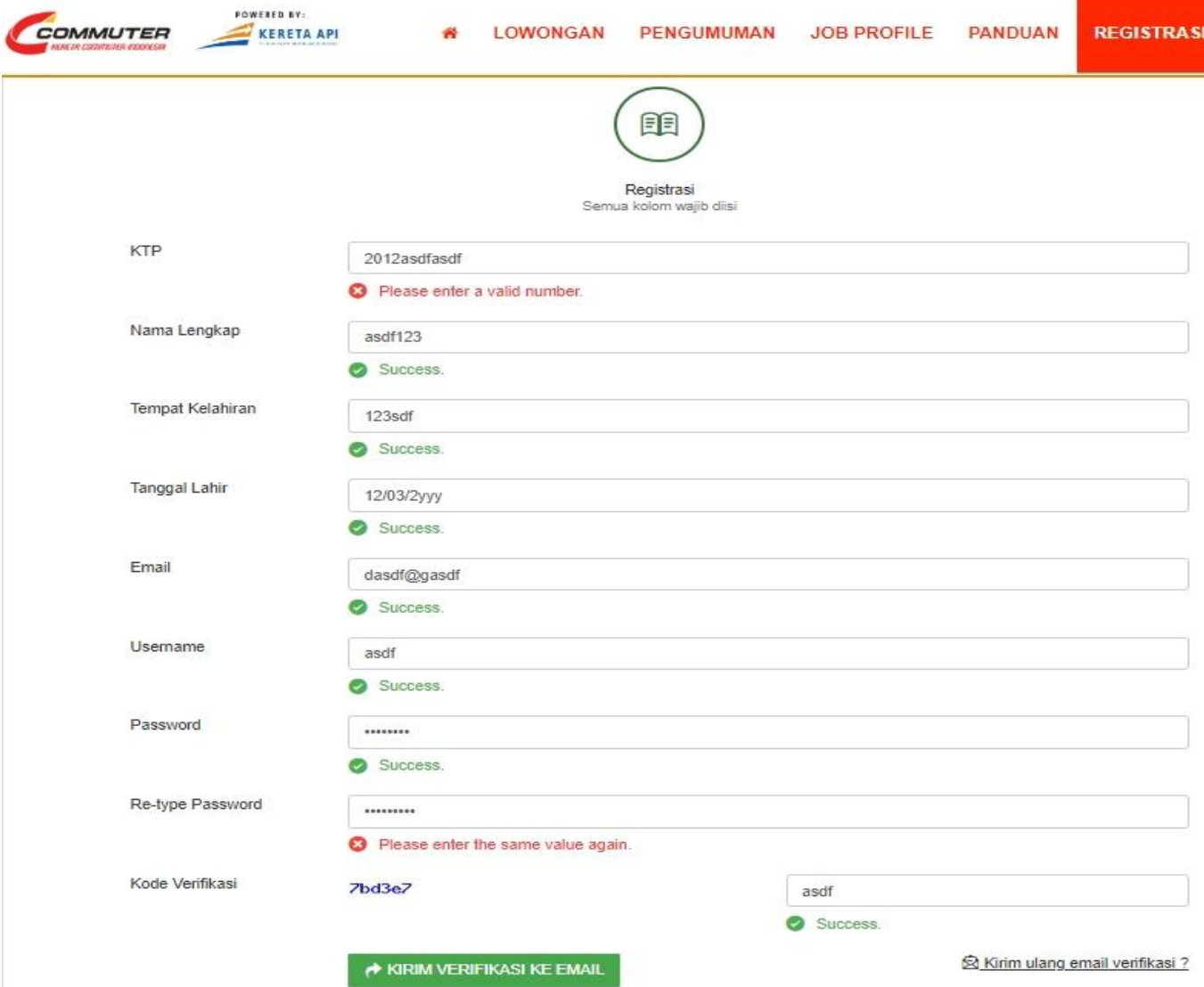

Gambar 3 Form Registrasi Commuter Line diisi data tidak valid 
Dari Gambar 3, Form Registrasi diisi dengan data yang tidak valid dan tidak sesuai pada ketentuan. Akibatnya data tidak akan masuk ke dalam database PT. Commuter Line dan tidak dapat diproses.

Tabel 1 Rancangan Test Case Form Tambah Jobdesk

\begin{tabular}{|c|l|l|}
\hline ID & \multicolumn{1}{|c|}{ Deskripsi Pengujian } & \multicolumn{1}{|c|}{ Hasil yang Diharapkan } \\
\hline A01 & $\begin{array}{l}\text { Pada Gambar 2. Kita isi dengan data valid dan } \\
\text { menekan tombol "Kirim Verikasi ke Email" }\end{array}$ & $\begin{array}{l}\text { Data tersimpan di database dan user } \\
\text { menerima email balasan dari PT. } \\
\text { Commuter Line }\end{array}$ \\
\hline A02 & $\begin{array}{l}\text { Pada Gambar 3. Kita isi dengan data tidak valid dan } \\
\text { menekan tombol "Kirim Verikasi ke Email" }\end{array}$ & $\begin{array}{l}\text { Data tidak tersimpan di database dan user } \\
\text { menerima feedback apa kesalahan dari } \\
\text { masukan user }\end{array}$ \\
\hline
\end{tabular}

\section{Hasil dan Pembahasan}

Tujuan dilaksanakan pengujian adalah untuk memastikan bahwa sistem yang dihasilkan sesuai dengan kebutuhan dan layak untuk digunakan (Arwaz, Putra, Putra, Kusumawijaya, \& Saifudin, 2019). Untuk membuktikan bahwa aplikasi yang dibuat telah sesuai maka perlu dilakukan eksekusi setiap uji kasus (test case) yang telah dirancang.

Pengujian dilakukan mengikuti deskripsi rancangan uji kasus (test case). Hasilnya dicatat di kolom hasil pengujian. Kesimpulan dibuat berdasarkan penilaian kesesuaian antara hasil pengujian dengan hasil yang diharapkan. Bila hasil pengujian sama dengan harapan maka disimpulkan Sesuai/Sukses. Bila hasil pengujian belum sama dengan yang diharapkan maka disimpulkan Salah/Gagal. Hasil dari pengujian yang telah dilakukan ditunjukkan pada Tabel 2.

Tabel 2 Tabel Hasil Pengujian

\begin{tabular}{|c|l|l|l|l|}
\hline ID & Deskripsi Pengujian & Hasil yang Diharapkan & \multicolumn{1}{|c|}{ Hasil Pengujian } & Status \\
\hline A01 & $\begin{array}{l}\text { Pada Gambar 2. Kita } \\
\text { isi dengan data valid } \\
\text { dan menekan tombol } \\
\text { "Kirim Verikasi ke } \\
\text { Email" }\end{array}$ & $\begin{array}{l}\text { Data tersimpan di database } \\
\text { dan } \text { user menerima email } \\
\text { balasan dari PT. Commuter } \\
\text { Line }\end{array}$ & $\begin{array}{l}\text { Menerima feedback } \\
\text { success saat pemasukan } \\
\text { data } \text { user }\end{array}$ & Sukses \\
\hline A02 & $\begin{array}{l}\text { Pada Gambar 3. Kita } \\
\text { isi dengan data tidak } \\
\text { valid dan menekan } \\
\text { tombol "Kirim } \\
\text { Verikasi ke Email" }\end{array}$ & $\begin{array}{l}\text { Data tidak tersimpan di } \\
\text { database dan } \text { user } \\
\text { menerima feedback apa } \\
\text { kesalahan dari pemasukan } \\
\text { user }\end{array}$ & $\begin{array}{l}\text { Menerima feedback } \\
\text { kesalahan masukan dari } \\
\text { pemasukan data } \text { user. } \\
\text { Tetapi sebagian dianggap } \\
\text { benar oleh sistem }\end{array}$ & Gagal \\
\hline
\end{tabular}

Pada sistem Aplikasi Form Pendaftaran Berbasis Web ini ada 1 form yang diuji dengan 9 kolom, setiap kolom diuji dengan mengisi data valid sebanyak $1 \mathrm{x}$, diuji lagi dengan data tidak valid sebanyak 1x. Jumlah kolom yang ditemukan adanya error atau bug pada proses pengujian fungsional.

Hasil pengujian yang telah didokumentasikan selanjutnya diserahkan ke programmer untuk dilakukan perbaikan. Sehingga setelah dilakukan pengujian dan perbaikan, aplikasi yang dibuat telah memenuhi semua persyaratan. Untuk meningkatkan fungsi dari perangkat lunak maka harus memiliki suatu prosedur yang jelas, agar mendapatkan hasil yang valid.

\section{Kesimpulan}

Sesuai pada pembahasan yang telah dibuat sebelumnya, dapat dibuat kesimpulan bahwa pengujian perangkat lunak secara Black Box yang hanya berfokus pada masukan dan keluaran dapat meunjukkan kesesuaian perangkat lunak yang dikembangkan dengan persyaratan sistem yang ditetapkan. Teknik Equivalance Partitions dapat membantu proses pembuatan kasus pengujian dan menentukan kualitas serta menemukan kesalahan 
yang ada, dan menjamin aplikasi yang diuji sesuai dengan fungsional yang diinginkan.

\section{Saran}

Berdasarkan proses pengujian dan hasil pembahasan pengujian perangkat lunak Sistem Aplikasi Informasi Data Kinerja masih perlu untuk dikembangkan. Adapun saran untuk pengembangan aplikasi berikutnya yaitu menggunakan metode Black Box Testing agar dapat mengetahui setiap detail perancangan dari pembuatan struktur perangkat lunak ini, serta dapat mencoba teknik-teknik pengujian Black Box Testing lainnya agar mengetahui kualitas perangkat lunak jauh lebih baik untuk menemukan kesalahan.

\section{Referensi}

Arochman, Darmawan, A. S., \& Santoso, F. H. (2016). Otomatisasi Desain Test Case Pengujian Perangkat Lunak Metode Black-Box Testing Dengan Teknik Equivalence Partitioning Menggunakan Algoritma Genetika. 47-55.

Arwaz, A. A., Putra, K., Putra, R., Kusumawijaya, T., \& Saifudin, A. (2019). Pengujian Black Box pada Aplikasi Sistem Seleksi Pemenang Tender Menggunakan Teknik Equivalence Partitions. Jurnal Teknologi Sistem Informasi dan Aplikasi, 2(4), 130-134. doi:10.32493/jtsi.v2i4.3708

Aziz, I. A., Setiawan, B., Khanh, R., Nurdiyansyah, G., \& Yulianti, Y. (2020). Pengujian Black Box pada Aplikasi Sistem Kasir Berbasis Website Menggunakan Teknik Equivalence Partitions. Jurnal Teknologi Sistem Informasi dan Aplikasi, 3(2), 10.32493/jtsi.v3i2.4693. doi:10.32493/jtsi.v3i2.4693

Debiyanti, D., Sutrisna, S., Budrio, B., Kamal, A. K., \& Yulianti, Y. (2020). Pengujian Black Box pada Perangkat Lunak Sistem Penilaian Mahasiswa Menggunakan Teknik Boundary Value Analysis. Jurnal Informatika Universitas Pamulang, $\quad$ 5(2), 162-166. doi:10.32493/informatika.v5i2.5446

Hanifah, U., Alit, R., \& Sugiarto, S. (2016). Penggunaan Metode Black Box Pada Pengujian Sistem Informasi Surat Keluar Masuk. SCAN - Jurnal Teknologi Informasi dan Komunikasi , 11(2), 33-40.
Hendri, H., Manurung, J. W., Ferian, R. A., Hanaatmoko, W. F., \& Yulianti, Y. (2020). Pengujian Black Box pada Aplikasi Sistem Informasi Pengelolaan Masjid Menggunakan Teknik Equivalence Partitions. Jurnal Teknologi Sistem Informasi dan Aplikasi, 3(2), 107-113. doi:10.32493/jtsi.v3i2.4694

Hidayat, T., \& Muttaqin, M. (2018). Pengujian Sistem Informasi Pendaftaran dan Pembayaran Wisuda Online menggunakan Black Box Testing dengan Metode Equivalence Partitioning dan Boundary Value Analysis. Jutis (Jurnal Teknik Informatika), 6(1), 25-29.

Ningrum, F. C., Suherman, D., Aryanti, S., Prasetya, H. A., \& Saifudin, A. (2019). Pengujian Black Box pada Aplikasi Sistem Seleksi Sales Terbaik Menggunakan Teknik Equivalence Partitions. Jurnal Informatika Universitas Pamulang, 4(4), 125-130.

Pratala, C. T., Asyer, E. M., Prayudi, I., \& Saifudin, A. (2020). Pengujian White Box pada Aplikasi Cash Flow Berbasis Android Menggunakan Teknik Basis Path. Jurnal Informatika Universitas Pamulang, 5(2), 111-119. doi:10.32493/informatika.v5i2.4713

Saifudin, A., \& Yulianti, Y. (2020). Dimensional Reduction on Cross Project Defect Prediction. Journal of Physics: Conference Series. 1477, hal. 022030. Tangerang: IOP Publishing. doi:10.1088/1742-6596/1477/3/032011

Taufiq, R., Magfiroh, D. A., Yusup, D., \& Yulianti, Y. (2020). Analisis dan Desain Sistem Informasi Pembayaran Sumbangan Pembinaan Pendidikan (SPP) di SMK Avicena Rajeg. Jurnal Teknologi Sistem Informasi dan Aplikasi, $\quad 3(1), \quad$ 15-21. doi:10.32493/jtsi.v3i1.4308

Wahyudi, R., Utami, E., \& Arief, M. R. (2016). Sistem Pakar E-Tourism Pada Dinas Pariwisata D.I.Y Menggunakan Metode Forward Chaining. Jurnal Ilmiah DASI, 17(2), 67-75.

Yulistina, S. R., Nurmala, T., Supriawan, R. M., Juni, S. H., \& Saifudin, A. (2020). Penerapan Teknik Boundary Value Analysis untuk Pengujian Aplikasi Penjualan Menggunakan Metode Black Box Testing. Jurnal Informatika Universitas Pamulang, 5(2), 129-135. doi:10.32493/informatika.v5i2.5366 